\title{
Application of Super-Twisting Sliding Mode Controllers in Direct Field-Oriented Control System of Six-Phase Induction Motor: Experimental Studies
}

Jacek Listwan

Department of Electrical Machines, Drives and Measurements, Faculty of Electrical

Engineering, Wroclaw University of Science and Technology, 19 Smoluchowskiego

St., 50-372 Wroclaw, Poland

Received January 30, 2018; Accepted July 07, 2018

Abstract: This paper presents the direct field-oriented control (DFOC) method of six-phase induction motor with the application of super-twisting sliding mode algorithm. The mathematical model of the six-phase induction motor has been described. The descriptions of the space vector modulation (SVM) method and the super-twisting algorithm have been presented. The DFOC method with super-twisting sliding mode controllers has been described. The experimental studies of the DFOC method with super-twisting controllers have been performed, and the results of these studies are presented and discussed.

Keywords: six-phase squirrel-cage induction motor • direct field-oriented control method • super-twisting sliding mode control • experimental studies

\section{Introduction}

The development of converter systems allows us to use multiphase induction motors instead of conventional threephase induction motors. Major advantages of multiphase induction motors are as follows: reduced torque ripples, greater efficiency, lowering of the stator current per phase and improved fault tolerance (Amimeur et al., 2010; Levi et al., 2007; Listwan, 2017; Listwan and Pienkowski, 2016a, 2016b).

In this paper, the direct field-oriented control (DFOC) system with the application of the second-order supertwisting sliding mode (STSM) controllers has been considered. The original contribution of this paper is the application of the STSM controllers in the DFOC system with six-phase induction motor and experimental investigation of this novel control system.

This paper is divided into seven sections. In Section 1, the introduction is presented. In Section 2, the mathematical model of the six-phase induction motor is described. The space vector modulation (SVM) method has been discussed in Section 3. In Section 4, the description of the STSM algorithm is presented. Section 5 deals with the description of the DFOC method with the application of STSM controllers. Experimental studies are presented and discussed in Section 6 . The paper is concluded with a short summary.

\section{Mathematical model of six-phase induction motor}

Mathematical model of six-phase squirrel-cage induction motor has been formulated on the basis of commonly used simplifying assumptions presented in detail in Amimeur et al. (2010), Levi et al. (2007), Listwan (2017) and 
Listwan and Pienkowski (2016a, 2016b). Mathematical model of six-phase induction motor in phase coordinate system is described by the set of differential equations with the coefficients changing as a function of angle rotation of the rotor. To simplify the mathematical model of the analysed six-phase induction motor, the equations expressed through phase variables can be transformed to equations with constant coefficients by the use of the appropriate transformation of variables.

The transformation of stator variables can be made by using the transformation matrices denoted as $[C]$ and $\left[D_{s}\right]$, and the transformation of rotor variables can be made by using the transformation matrices denoted as $[C]$ and $\left[D_{r}\right]$ (Levi et al., 2007).

After applying the transformation matrices denoted as $[C]$ to the stator and rotor equations, the original six-phase system can be decomposed into decoupled systems (Levi et al., 2007; Listwan, 2017; Listwan and Pienkowski, $2016 \mathrm{a}, 2016 \mathrm{~b})$ : the stationary $\alpha-\beta$ coordinate system, the additional coordinate system $z 1-z 2$ and the system of zero components (there are two zero components for the considered induction motor).

The transformation matrix $[C]$ for the stator and rotor of the six-phase induction motor is defined as follows (Levi et al., 2007):

$$
[C]=\sqrt{\frac{2}{6}}\left[\begin{array}{cccccc}
1 & \cos \alpha & \cos 2 \alpha & \cos 3 \alpha & \cos 4 \alpha & \cos 5 \alpha \\
0 & \sin \alpha & \sin 2 \alpha & \sin 3 \alpha & \sin 4 \alpha & \sin 5 \alpha \\
1 & \cos 2 \alpha & \cos 4 \alpha & \cos 6 \alpha & \cos 8 \alpha & \cos 10 \alpha \\
0 & \sin 2 \alpha & \sin 4 \alpha & \sin 6 \alpha & \sin 8 \alpha & \sin 10 \alpha \\
1 / \sqrt{2} & 1 / \sqrt{2} & 1 / \sqrt{2} & 1 / \sqrt{2} & 1 / \sqrt{2} & 1 / \sqrt{2} \\
1 / \sqrt{2} & -1 / \sqrt{2} & 1 / \sqrt{2} & -1 / \sqrt{2} & 1 / \sqrt{2} & -1 / \sqrt{2}
\end{array}\right]
$$

where $\alpha=2 \pi / 6$ is the electrical angle between the axes of the machine phase windings.

The components determined in the coordinate system $\alpha-\beta$ can be transformed by using the $[D]$ transformation matrix presented as follows to the general common $x-y$ coordinate system, which rotates at arbitrary angular speed $\omega_{k}$. The elements of the $\left[D_{s}\right]$ and $\left[D_{r}\right]$ transformation matrices are defined as follows (Levi et al., 2007):

$$
\begin{aligned}
& {\left[D_{s}\right]=\left[D_{s}\left(\vartheta_{k}\right)\right]=\left[\begin{array}{cccc}
\cos \vartheta_{k} & \sin \vartheta_{k} & & \\
-\sin \vartheta_{k} & \cos \vartheta_{k} & & \\
& 1 & & \\
& & 1 & \\
& & & 1
\end{array}\right]} \\
& {\left[D_{r}\right]=\left[D_{r}\left(\vartheta_{k}-\phi_{e}\right)\right]=\left[\begin{array}{cccc}
\cos \left(\vartheta_{k}-\phi_{e}\right) & \sin \left(\vartheta_{k}-\phi_{e}\right) & & \\
-\sin \left(\vartheta_{k}-\phi_{e}\right) & \cos \left(\vartheta_{k}-\phi_{e}\right) & & \\
& & 1 & 1
\end{array}\right]}
\end{aligned}
$$

where $\omega_{k}$ is the arbitrary angular speed of the coordinate system relative to the stator; $\vartheta_{k}={ }_{0}^{\mathrm{t}} \int \omega_{k} \mathrm{dt}$.

The transformations of the phase electromagnetic variables of the stator of the six-phase induction motor into the $x-y$ coordinate system and into various coordinate systems can be represented by the exemplary dependencies as presented in the following equation. These dependencies were formulated for motor voltages, but the same 
relationships can be applied to other electromagnetic variables of the stator and rotor of the six-phase induction motor.

$$
\left[\begin{array}{l}
u_{s x} \\
u_{s y} \\
u_{s z 1} \\
u_{s z 2} \\
u_{s 01} \\
u_{s 02}
\end{array}\right]=\left[D_{s}\right] \cdot\left[\begin{array}{l}
u_{s \alpha} \\
u_{s \beta} \\
u_{s z 1} \\
u_{s z 2} \\
u_{s 01} \\
u_{s 02}
\end{array}\right]=\left[D_{s}\right] \cdot[C] \cdot\left[\begin{array}{l}
u_{s 1} \\
u_{s 2} \\
u_{s 3} \\
u_{s 4} \\
u_{s 5} \\
u_{s 6}
\end{array}\right]
$$

The equations of six-phase induction motor after using the transformation matrices presented earlier have the following form (Levi et al., 2007; Listwan, 2017; Listwan and Pienkowski, 2016a, 2016b):

- The voltage equations of the stator and rotor in the basic $x-y$ coordinate system which rotates relative to the stator at arbitrary angular speed $\omega_{k}$ :

$$
\begin{gathered}
u_{s x}=R_{s} i_{s x}-\omega_{k} \psi_{s y}+\frac{d}{d t} \psi_{s x} \\
u_{s y}=R_{s} i_{s y}+\omega_{k} \psi_{s x}+\frac{d}{d t} \psi_{s y} \\
0=R_{r} i_{r x}-\left(\omega_{k}-\omega_{e}\right) \psi_{r y}+\frac{d}{d t} \psi_{r x} \\
0=R_{r} i_{r y}+\left(\omega_{k}-\omega_{e}\right) \psi_{r x}+\frac{d}{d t} \psi_{r y}
\end{gathered}
$$

- The stator voltage equations in the additional coordinate system $z 1-z 2$ :

$$
\begin{aligned}
& u_{s z 1}=R_{s} i_{s z 1}+\frac{d}{d} \psi_{s z 1} \\
& u_{s z 2}=R_{s} i_{s z 2}+\frac{d}{d t} \psi_{s z 2}
\end{aligned}
$$

- The equation of the electromagnetic torque:

$$
T_{e}=\frac{6}{2} p_{b}\left(\psi_{s x} i_{s y}-\psi_{s y} i_{s x}\right)
$$

- The mechanical motion equation:

$$
T_{e}-T_{m}=J_{m} \cdot \frac{d}{d t} \omega_{m}
$$

where $u_{s 1}-u_{s 6}$ are the stator voltages in the phase coordinate system; $u_{s x}, u_{s y}, u_{s z 1}, u_{s z 2}, u_{s 01}$ and $u_{s 02}$ are the components of the stator voltage vectors in the $x-y$ coordinate system, $z 1-z 2$ coordinate system and the system of zero components; $i_{s x}, i_{s y}, i_{s z}, i_{s z 2}, i_{r x}$ and $i_{r y}$ are the components of the stator and rotor current vectors in the $x-y$ and $z 1-z 2$ coordinate systems; $\psi_{s x}, \psi_{s v}, \psi_{s z z}, \psi_{s z 2}, \psi_{r x}$ and $\psi_{r y}$ are the components of the stator and rotor flux linkage vectors in the $x-y$ and $z 1-z 2$ coordinate systems; $p_{b}$ is the number of motor pole pairs; $\omega_{k}$ is the arbitrary angular speed of the coordinate system relative to the stator; $\omega_{m}$ is the mechanical angular speed of the motor; $\omega_{e}=\omega_{m} \cdot p_{b}$ is the electrical angular speed of the motor; $T_{e}$ is the motor electromagnetic torque; $R_{s}$ and $R_{r}$ are the stator and rotor phase resistance, respectively; $T_{m}$ is the load torque; $J_{m}$ is the inertia of the drive system. 


\section{SVM method}

In the analyzed DFOC method, it is assumed that six-phase induction motor is controlled by two-level six-phase voltage source inverter (VSI).

Voltage space vectors generated by the six-phase VSI in the stationary $\left(\omega_{k}=0\right)$ rectangular coordinate system $\alpha-\beta$ and in the $z 1-z 2$ additional coordinate system can be determined in the general form (Listwan and Pienkowski, 2016):

$$
\begin{aligned}
& \underline{u}_{s \alpha \beta}=u_{s \alpha}+j u_{s \beta}=\frac{2}{6}\left(S_{1}+\underline{a}_{2}+\underline{a}^{2} S_{3}+\underline{a}^{3} S_{4}+\underline{a}^{4} S_{5}+\underline{a}^{5} S_{6}\right) \cdot u_{d} \\
& \underline{u}_{s z 1 z 2}=u_{s z 1}+j u_{s z 2}=\frac{2}{6}\left(S_{1}+\underline{a}^{2} S_{2}+\underline{a}^{4} S_{3}+\underline{a}^{6} S_{4}+\underline{a}^{2} S_{5}+\underline{a}^{4} S_{6}\right) \cdot u_{d}
\end{aligned}
$$

where $a=\exp (j 2 \pi / 6) ; S_{1}, \ldots, S_{6}$ are the switching functions of the switches of the six-phase VSI $\left(S_{i}=0\right.$ or $\left.S_{i}=1, i=1, \ldots, 6\right)$ and $u_{d}$ is the voltage of the DC link of the VSI.

Voltage space vectors generated by the six-phase VSI in the coordinate system $\alpha-\beta$ are shown in Fig. 1(a), and voltage space vectors generated in the coordinate system $z 1-z 2$ are shown in Fig. 1(b).
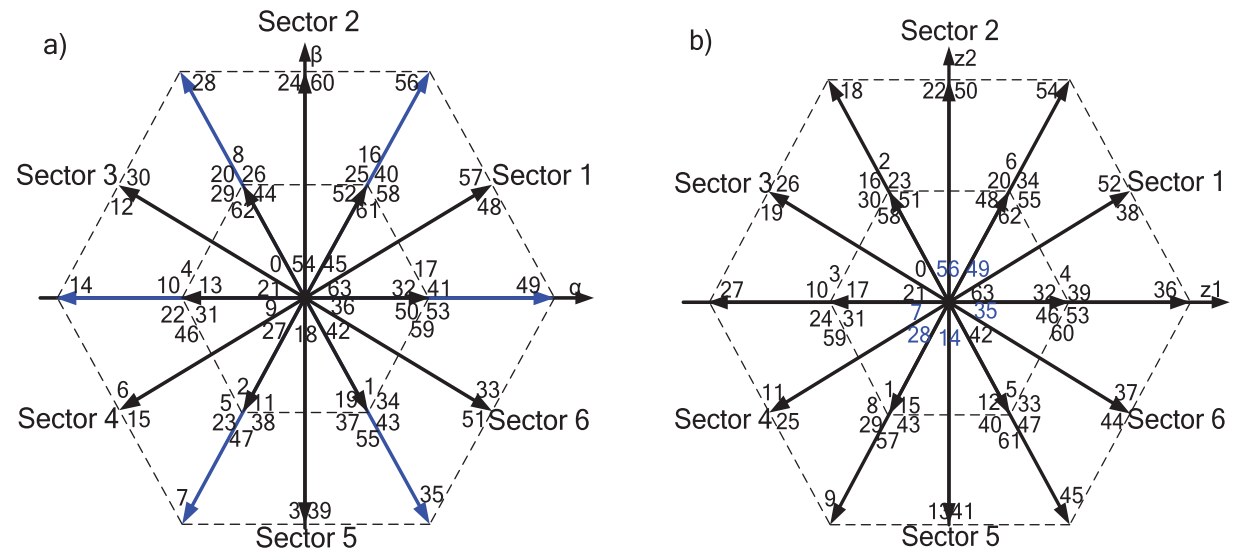

Fig. 1. Voltage space vectors generated by six-phase VSI in the coordinate systems: (a) $\alpha-\beta$ and (b) $z 1-z 2$.

Voltage space vectors generated by the six-phase VSI can be considered in the stationary rectangular coordinate system $\alpha-\beta$ and in the $z 1-z 2$ additional coordinate system. For six-phase VSI, as shown in Fig. 1, there are totally 64 vectors: 60 active vectors and four zero vectors in $\alpha-\beta$ and $z 1-z 2$ coordinate systems. In this paper, the modulation method with the use of two long active vectors from the same sector and two zero vectors has been applied (Listwan and Pienkowski, 2016). The voltage vectors used in the SVM have been marked in blue colour.

Switching times of voltage vectors are calculated according to the following equations for the sector I (Listwan and Pienkowski, 2016):

$$
\begin{gathered}
\underline{u}_{\text {sref }} \cdot T_{s}=\underline{u}_{49} \cdot t_{1}+\underline{u}_{56} \cdot t_{2}+\underline{u}_{0} \cdot t_{0} \\
t_{0}=T_{s}-t_{1}-t_{2}
\end{gathered}
$$

where $u_{\text {sref }}$ is the reference voltage vector; $u_{49}$ and $u_{56}$ are the long active vectors; $t_{1}$ and $t_{2}$ are the switching times of long voltage vectors; $t_{0}$ is the switching time of zero voltage vector; $T_{s}$ is the switching period. 


\section{Description of the STSM algorithm}

The STSM control method maintains the advantages of the conventional sliding mode control methods (Utkin et al., 1999) and allows for the elimination of the undesirable phenomena of chattering (Beltran et al., 2012; Benelghali et al., 2009; Gonzales et al., 2012; Lascu and Blaabjerg, 2014). The output signal from controller of this type is comparable with the control signal obtained from linear proportional-integral (PI) controllers (Beltran et al., 2012; Benelghali et al., 2009; Gonzales et al., 2012; Lascu and Blaabjerg, 2014).

The control law of the STSM controller can be defined as follows (Beltran et al., 2012; Benelghali et al., 2009; Gonzales et al., 2012; Lascu and Blaabjerg, 2014):

$$
\begin{gathered}
u=K_{p} \cdot|s|^{r} \cdot \operatorname{sgn}(s)+u_{1} \\
\frac{d u_{1}}{d t}=K_{i} \cdot \operatorname{sgn}(s)
\end{gathered}
$$

where $s$ is the switching function determined for the STSM controller; $K_{p}$ and $K_{i}$ are the coefficients of the proportional and integral parts of the STSM controller, respectively; $r$ is the exponent defined for the STSM controller.

The graphical representation of the control law of the STSM controller is shown in Fig. 2.

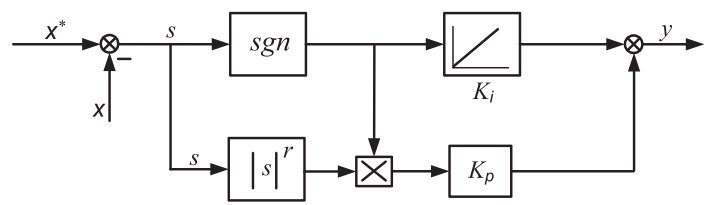

Fig. 2. Graphical representation of the control law of the STSM controller

The values of coefficients of the proportional and integral parts of all analyzed super-twisting controllers and value of the exponent $r$ have been determined according to the procedure presented in detail in Lascu and Blaabjerg (2014). The value of the exponent $r$ has an impact on the dynamics of the control structure with STSM controllers. This exponent can have a value between zero and one. In the analyzed control structure, its value was assumed as 0.5. The applied tuning procedure allows for ensuring the stability of the control system (Lascu and Blaabjerg, 2014).

The procedure for determining the coefficients $K_{p}$ and $K_{i}$ of the super-twisting controllers is based on the analysis of equations for the nonlinear control system and the equations of the output signals. These equations in the matrix form are presented as follows (Lascu and Blaabjerg, 2014; Utkin et al., 1999):

$$
\frac{d x}{d t}=a(x, t)+b(x, t) \cdot u, \quad y=c(x, t)
$$

where $x$ is the state vector of the system; $a(x, t), b(x, t)$ and $c(x, t)$ are the vector functions; $u$ is the vector of input control signals; $y$ is the vector of output control signals.

The second time derivative of equations for the output signals has the matrix form presented as follows:

$$
\frac{d^{2} y}{d t^{2}}=A(x, t)+B(x, t) \cdot \frac{d}{d t} u
$$

The bounds of $A(x, t)$ and $B(x, t)$ of the second derivative of $y$ can be labelled as $A_{m}, A_{M}, B_{m}$ and $B_{M}$, where $A_{M}$ and $B_{M}$ are upper bounds and $A_{m}$ and $B_{m}$ are lower bounds. The coefficients $K_{p}$ and $K_{i}$ are determined for all STSM controllers according to the equations presented as follows (Lascu and Blaabjerg, 2014): 


$$
\left.K_{p}\right\rangle \frac{A_{M}}{B_{m}}, \quad K_{i} \geq \frac{4 \cdot A_{M}}{B_{m}^{2}} \cdot \frac{B_{M}\left(K_{p}+A_{M}\right)}{B_{m}\left(K_{p}-A_{M}\right)}
$$

In this paper, the procedure for determining the coefficients $K_{p}$ and $K_{i}$ for the super-twisting controller of the motor speed has been presented. The same principle has been used to determine the values of the coefficients $K_{p}$ and $K_{i}$ for the super-twisting controllers of the magnitude of the rotor flux vector and controllers of the $i_{s x}$ and $i_{s y}$ components of the stator current vector used in the DFOC system with six-phase induction motor.

\section{STSM DFOC method}

The DFOC method of six-phase induction motor with the application of STSM controllers is shown in Fig. 3. In this control system, the motor speed, the magnitude of the rotor flux vector and the components $i_{s x}$ and $i_{s y}$ of the stator current vector are controlled by the STSM controllers.

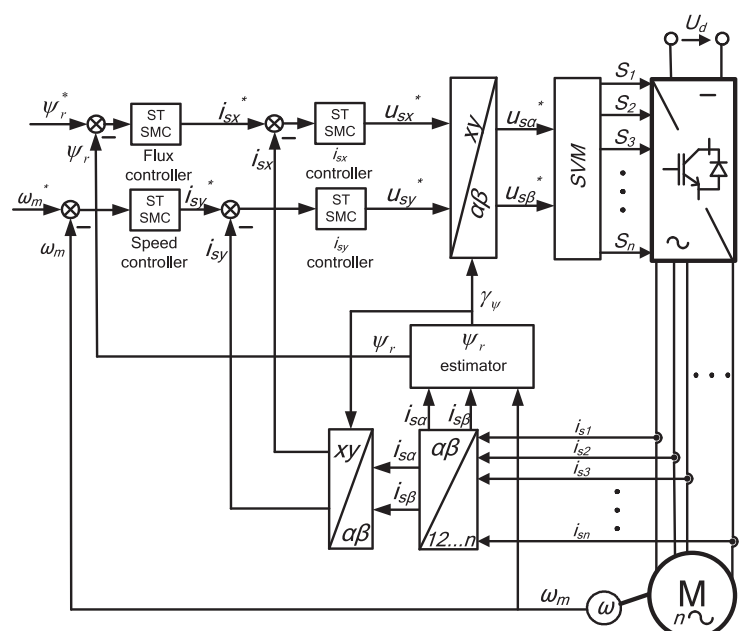

Fig. 3. DFOC system of six-phase induction motor with the application of STSM controllers

In the outer control loop of the motor speed, the reference value of the motor speed is compared with the measured motor speed. The switching function for motor speed controller can be specified as follows (Lascu and Blaabjerg, 2014; Listwan, 2017; Utkin et al., 1999):

$$
s_{\omega m}=\omega_{m}^{*}-\omega_{m}
$$

The controller of the motor angular speed determines the reference $i_{s y}{ }^{*}$ component of stator current vector, which is responsible for the control of motor electromagnetic torque. The output signal from this controller is determined by the following system of equations (Lascu and Blaabjerg, 2014):

$$
\begin{gathered}
i_{s y}^{*}=K_{p \omega} \cdot\left|s_{\omega m}\right|^{\frac{1}{2}} \cdot \operatorname{sgn}\left(s_{\omega m}\right)+i_{s y 1}^{*} \\
\frac{d i_{s y 1}^{*}}{d t}=K_{i \omega} \cdot \operatorname{sgn}\left(s_{\omega m}\right)
\end{gathered}
$$

where $K_{p \omega}$ and $K_{i \omega}$ are the coefficients of the proportional and integral part of the STSM speed controller, respectively. The procedure for determining the values of the coefficients $K_{p \omega}$ and $K_{i \omega}$ is given in the following sections. 
The second derivative of the switching function for the controller of the motor angular speed can be defined as follows:

$$
\frac{d^{2}}{d t^{2}} s_{\omega m}=\frac{d^{2}}{d t^{2}} \omega_{m}^{*}-\frac{d^{2}}{d t^{2}} \omega_{m}
$$

Equation (18) after the substitution of the converted mechanical motion equation (8) and the equation of the motor electromagnetic torque (7) and other algebraic manipulations takes the following form:

$$
\frac{d^{2}}{d t^{2}} s_{\omega m}=\frac{d^{2}}{d t^{2}} \omega_{m}^{*}-\frac{d}{d t} \frac{\frac{6}{2} p_{b} i_{s y} \psi_{r}-T_{m}}{J_{m}}
$$

The second derivative of the motor speed can be presented in the following form:

$$
\frac{d^{2}}{d t^{2}} \omega_{m}=\frac{d}{d t} \frac{\frac{6}{2} p_{b} i_{s y} \psi_{r}-T_{m}}{J_{m}}
$$

which gives the coefficients $A$ and $B$ :

$$
A=\frac{d}{d t} \frac{T_{m}}{J_{m}} \quad \text { and } \quad B=\frac{6}{2} p_{b} \frac{d}{d t} \frac{i_{s y} \psi_{r}}{J_{m}}
$$

The coefficients $A$ and $B$ are used for the determination of the coefficients $K_{p \omega}$ and $K_{i \omega}$ according to equation (15).

In the outer control loop of the rotor flux vector, the reference value of the magnitude of the rotor flux vector is compared with the estimated value. The switching function for rotor flux vector controller can be specified as follows (Lascu and Blaabjerg, 2014; Listwan, 2017; Utkin et al., 1999):

$$
s_{\psi r}=\psi_{r}^{*}-\psi_{r}
$$

This controller determines the reference component $i_{s x}^{*}$ of stator current vector, which is responsible for the control of the magnitude of the rotor flux vector. The output signal from the controller of the magnitude of the rotor flux vector is determined by the following system of equations (Lascu and Blaabjerg, 2014):

$$
\begin{gathered}
i_{s x}^{*}=K_{p \psi} \cdot\left|s_{\psi r}\right|^{\frac{1}{2}} \cdot \operatorname{sgn}\left(s_{\psi r}\right)+i_{s x 1}^{*} \\
\frac{d i_{s x 1}^{*}}{d t}=K_{i \psi} \cdot \operatorname{sgn}\left(s_{\psi r}\right)
\end{gathered}
$$

where $K_{p \psi}$ and $K_{i \psi}$ are the coefficients of the proportional and integral parts of the STSM rotor flux controller, respectively.

In the analyzed DFOC system with super-twisting controllers, the two inner control loops have also been applied: the control loop for the component $i_{s x}$ of the stator current vector and the control loop for the component $i_{s y}$ of the stator current vector.

In the inner control loop of the $i_{s x}$ component of the stator current vector, the reference value of this component is compared with the measured transformed value. The switching function for the controller of $i_{s x}$ component of stator current vector can be specified as follows (Lascu and Blaabjerg, 2014; Listwan, 2017; Utkin et al., 1999):

$$
s_{i s x}=i_{s x}^{*}-i_{s x}
$$


The controller of $i_{s x}$ component of the stator current vector determines the reference component $u_{s x}$ of stator voltage vector. The output signal from this controller is determined by the following system of equations (Lascu and Blaabjerg, 2014):

$$
\begin{gathered}
u_{s x}^{*}=K_{p i s x} \cdot\left|s_{i s x}\right|^{\frac{1}{2}} \cdot \operatorname{sgn}\left(s_{i s x}\right)+u_{s x 1}^{*} \\
\frac{d u_{s x 1}^{*}}{d t}=K_{i i s x} \cdot \operatorname{sgn}\left(s_{i s x}\right)
\end{gathered}
$$

where $K_{p i s x}$ and $K_{i i s x}$ are the coefficients of the proportional and integral parts of the STSM controller of component $i_{s x}$ of stator current vector, respectively.

In the inner control loop of the $i_{s y}$ component of the stator current vector, the reference value of this component is compared with the measured transformed value. The switching function for the controller of $i_{s y}$ controller of stator current vector can be specified as follows (Lascu and Blaabjerg, 2014; Listwan, 2017; Utkin et al., 1999):

$$
s_{i s y}=i_{s y}^{*}-i_{s y}
$$

The controller of $i_{s y}$ component of the stator current vector determines the reference component $u_{s y}$ of stator voltage vector. The output signal from this controller is determined by the following system of equations (Lascu and Blaabjerg, 2014):

$$
\begin{gathered}
u_{s y}^{*}=K_{p i s y} \cdot\left|s_{i s y}\right|^{\frac{1}{2}} \cdot \operatorname{sgn}\left(s_{i s y}\right)+u_{s y 1}^{*} \\
\frac{d u_{s y 1}^{*}}{d t}=K_{i i s y} \cdot \operatorname{sgn}\left(s_{i s y}\right)
\end{gathered}
$$

where $K_{\text {pisy }}$ and $K_{\text {iisy }}$ are the coefficients of the proportional and integral parts of the STSM controller of component $i_{s y}$ of stator current vector, respectively.

The reference values $u_{s x}{ }^{*}$ and $u_{s y}{ }^{*}$ are transformed to the $\alpha-\beta$ coordinate system and given to the SVM, which sets the switching states of the six-phase VSI.

The instantaneous magnitude of the rotor flux vector and the instantaneous angle of the rotor flux vector are determined by the flux estimator. The vector of the rotor flux has been estimated by the current model of the induction motor based on the measured stator currents and measured motor speed (Orlowska-Kowalska, 2003).

\section{Experimental studies of STSM DFOC method}

The experimental studies of the considered control method have been carried out using the specially designed and built laboratory set-up. The block diagram of the experimental set-up is shown in Fig. 4, and the image of the drive system with six-phase induction motor with the indication of the most important elements is shown in Fig. 5 .

The experimental system consists of the six-phase squirrel-cage induction motor, slip-ring induction motor used as the load machine, the system of six-phase VSI consisting of the two three-phase VSIs, the measuring system of six stator currents with the LEM-type sensors, the incremental encoder, the PC computer with the ControlDesk Software and with the dSpace 1104 Processor card and control boards that change the signals from the processor to the signals transmitted through the optical fibres. The values of the load torque have been regulated by the braking resistance including in the rotor windings and the value of the DC current in the stator windings of the slip-ring induction motor. The load torque has been activated after switch on the DC current.

Experimental studies were carried out for the six-phase squirrel-cage induction motor with the following data and parameters: $P_{N}=1.5 \mathrm{~kW}, U_{f N}=230 \mathrm{~V}, f_{N}=50 \mathrm{~Hz}, p_{b}=2, R_{s}=7.8 \Omega, R_{r}=11 \Omega, L_{l s}=L_{l r}=0.06 \mathrm{Henr}(\mathrm{H}), L_{m}=0.75 \mathrm{Henr}(\mathrm{H})$. 


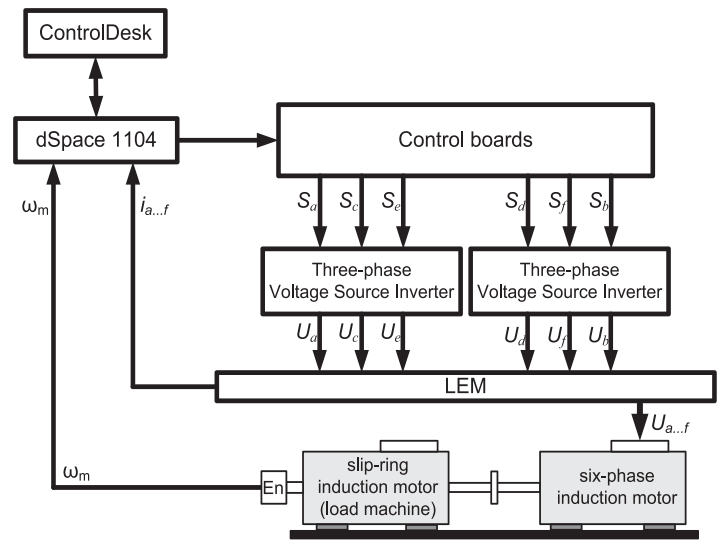

Fig. 4. Block diagram of the experimental set-up

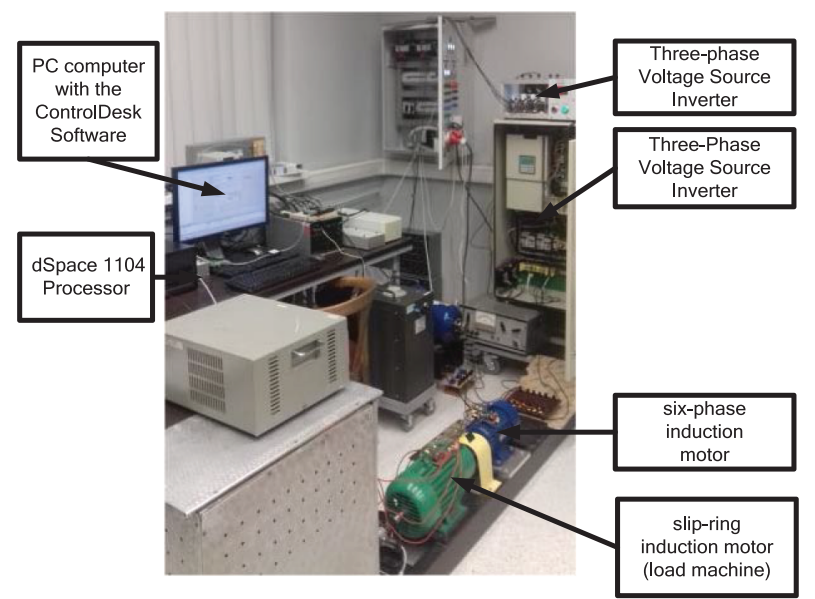

Fig. 5. Image of the laboratory set-up with six-phase induction motor

The experimental waveforms of the reference and measured speed of the six-phase induction motor are shown in Fig. 6 in order to compare the performance of the DFOC system with application of the STSM controllers with the performance of the DFOC system with application of the PI controllers. The start-up and the reverse operation of the motor have been presented. The load torque has been forced after reaching the set value of speed. It can be stated that during the start-up for the DFOC system with STSM controllers, the measured speed follows the reference speed faster than for the structure with PI controllers. After switching off the load torque in the DFOC system with STSM controllers, the amplitudes of the oscillations of the speed are smaller and occur in a shorter time period in comparison with the oscillations obtained for the DFOC with PI controllers.

The experimental waveform of the electromagnetic torque of six-phase induction motor for DFOC system with the application of STSM controllers is shown in Fig. 7. During the start-up, the electromagnetic torque has the biggest value. After determining the set speed, the value of the electromagnetic torque is equal to the value of idling state. At the load condition, the electromagnetic torque becomes identical as the load torque.

The experimental waveforms of the $i_{s y}{ }^{*}$ reference component of the stator current vector, measured $i_{s y}$ component of the stator current vector and the difference $\Delta i_{s y}$ between these current components are shown in Fig. 8 . These waveforms demonstrate that the analyzed second-order sliding mode controller allows to obtain control signals with the waveforms similar to the output signals from linear PI controller. It can be stated that the $i_{s v}$ component of the stator current vector is controlled properly at the given reference value.

The experimental waveforms of all stator phase currents of six-phase induction motor for the considered control system are shown in Fig. 9. The amplitudes of the stator phase currents depend on the state of the drive system and the value of the load torque. 
a)

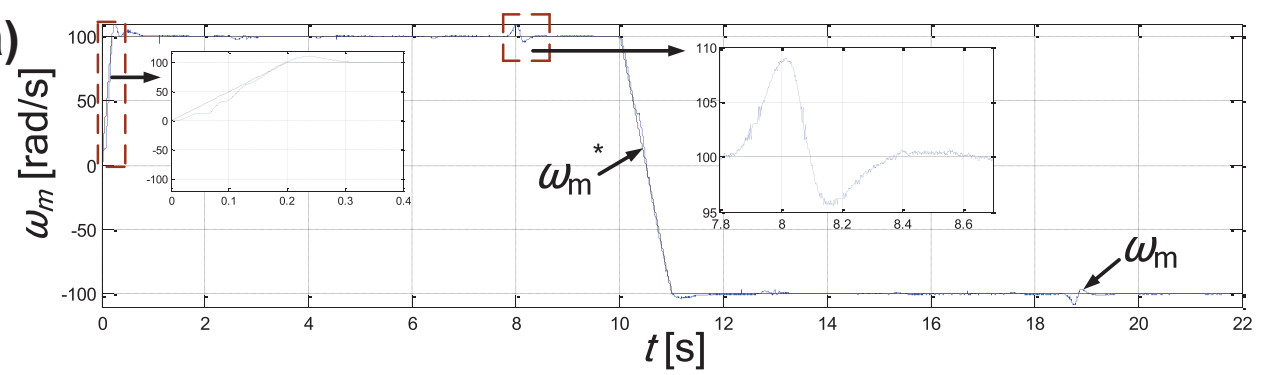

b)

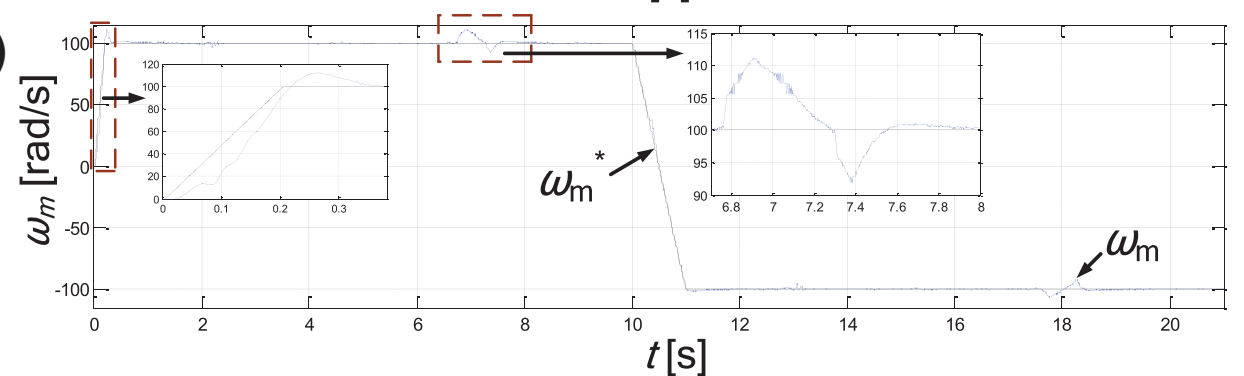

Fig. 6. Experimental results: (a) the waveforms of speeds of six-phase induction motor for DFOC system with the application of STSM controllers; (b) the waveforms of speeds of six-phase induction motor for DFOC system with the application of PI controllers

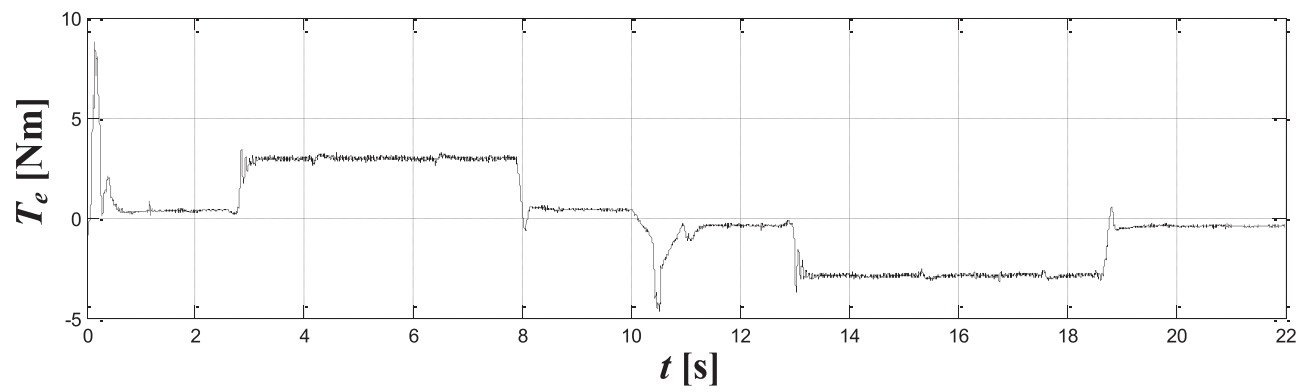

Fig. 7. Experimental waveform of the electromagnetic torque of six-phase induction motor for DFOC system with STSM controllers

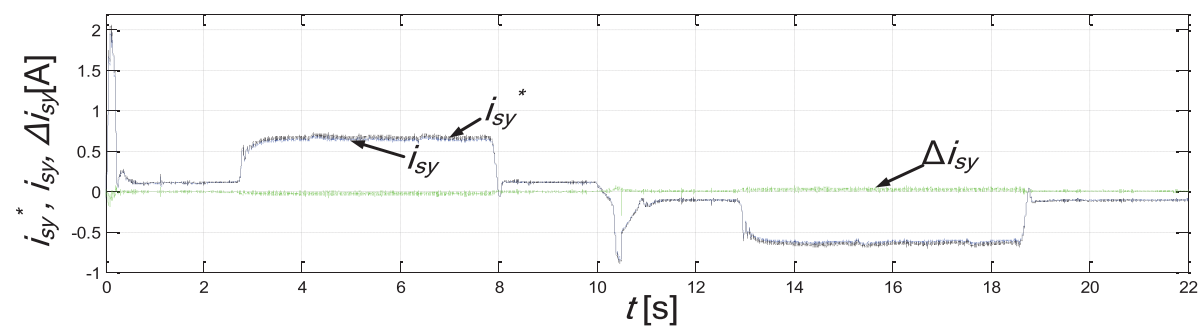

Fig. 8. Experimental waveforms of the reference and measured $i_{s y}$ component of stator current vector and the waveform of the current error $\Delta i_{s y}$ of the six-phase induction motor

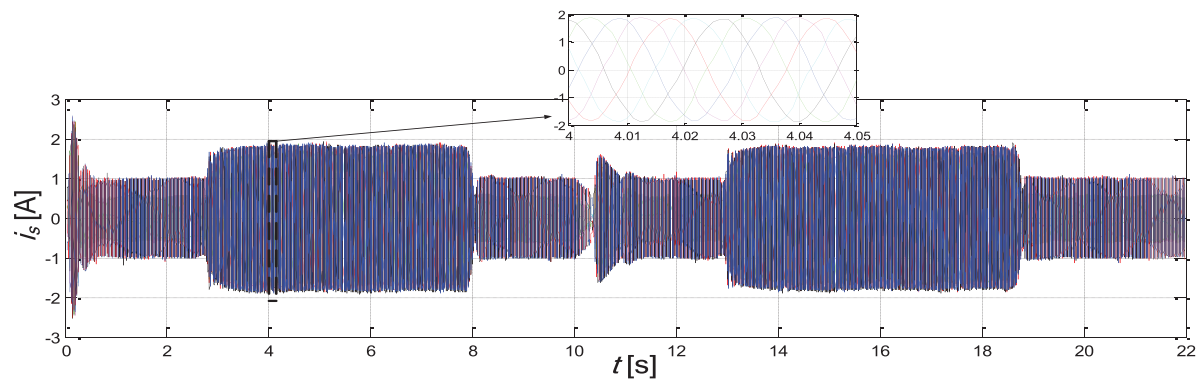

Fig. 9. Stator phase currents of the six-phase induction motor for DFOC system with STSM controllers 
The trajectory of the estimated magnitude of the rotor flux vector is shown in Fig. 10(a). It can be stated that the rotor flux vector is controlled properly at the nominal value. The waveforms of the stator current components in the $z 1-z 2$ coordinate system are shown in Fig. 10(b) and (c). The amplitudes of the current vector components in the $z 1-z 2$ coordinate system have small amplitudes and do not contribute to the performance of the six-phase induction motor.
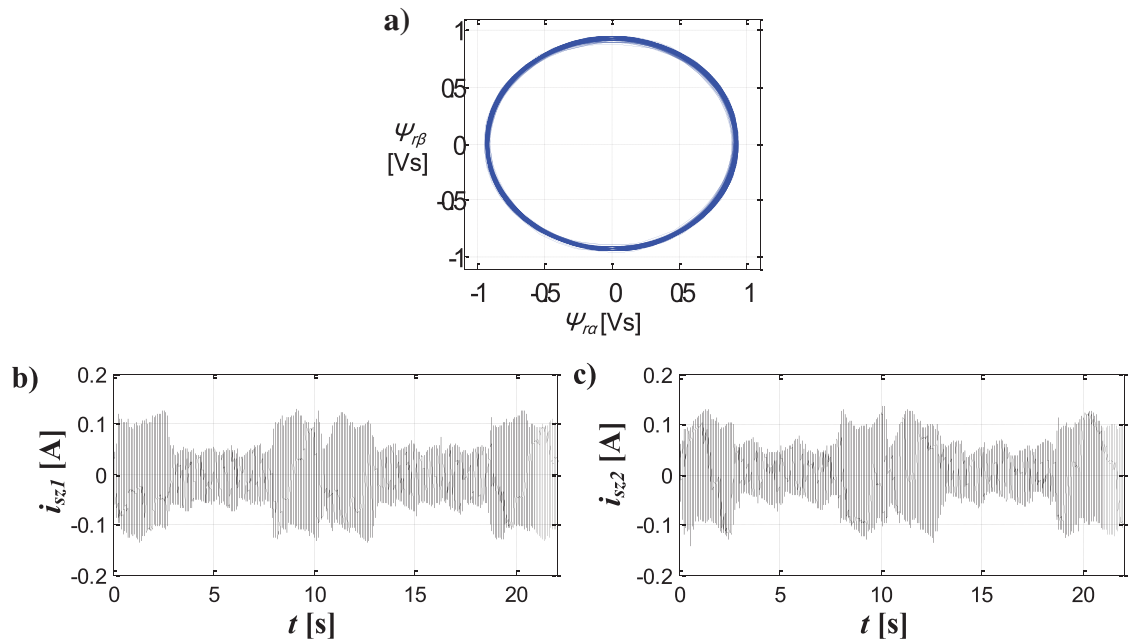

Fig. 10. Experimental results of the DFOC system of six-phase induction motor with the application of STSM controllers: (a) the trajectory of the estimated magnitude of the rotor flux vector; (b) the $z 1$ component of the stator current vector and (c) the $z 2$ component of the stator current vector

\section{Conclusions}

The DFOC system with the application of STSM controllers has been presented and described in this paper. The design procedure of the super-twisting controllers and the procedure for determining the values of the coefficients $K_{p}$ and $K_{i}$ for the speed controller have been presented. The performance of the drive system with the super-twisting controllers has been demonstrated through experimental studies.

The performance of the motor speed, motor electromagnetic torque, stator currents, rotor flux vector and components of stator current vector of the six-phase induction motor have been investigated. It has been stated that the measured motor speed follows the reference speed with great accuracy. It has been observed that there was a rapid torque response during transient states of the drive system. The amplitudes of the stator phase currents depend on the working condition of the drive system. The rotor flux vector is controlled properly at the nominal value. The waveform of the $y$ component of the stator current vector demonstrates that the super-twisting sliding mode control algorithm allows to obtain the control signals comparable with the control signals received from conventional linear PI controllers.

The conducted experimental studies demonstrated the good performance of the DFOC system with STSM controllers. The presented speed trajectories for DFOC with the application of STSM controllers confirm obtaining better control accuracy in comparison with obtained results for DFOC system with the application of PI controllers.

\section{References}

Amimeur, H., Abdessemed, R., Aouzellag, D., Merabet, E. and Hamoudi, F. (2010). A Sliding Mode Control associated to the Field-Oriented Control of DualStator Induction Motor Drives. Journal of Electrical Engineering, 10(3), pp. 7-12.

Beltran, B., Benbouzid, M. and Ahmed-Ali, T. (2012). Second-Order Sliding-Mode Control of a Doubly
Fed Induction Generator Driven Wind Turbine. IEEE Transactions on Energy Conversion, 27(2), pp. 261-269.

Benelghali, S., Benbouzid, M., Charpentier, J., AhmedAli, T. and Munteanu, I. (2009). High-order sliding mode control of a marine current turbine driven permanent magnet synchronous generator. 
In: Proceedings of the 2009 IEEE International Electric Machines and Drives Conference, Miami, FL, USA, 3-6 May 2009.

Gonzales, T., Moreno, A. and Fridman, L. (2012). Variable gain super-twisting sliding mode control. IEEE Transactions on Automatic Control, 57(8), pp. 2100-2105.

Lascu, C. and Blaabjerg, F. (2014). Super-twisting slidingmode direct torque control of induction machine drives. In: Proceedings of the 2014 IEEE Energy Conversion Congress and Exposition (ECCE), Pittsburgh, PA, USA, 14-18 September 2014.

Levi, E., Bojoi, R., Profumo, F., Toliyat, H. A. and Williamson, S. (2007). Multiphase Induction Motor Drives - A Technology Status Review. IET Electric Power Application, 1(4), pp. 489-516.

Listwan, J. (2017). Experimental studies of supertwisting sliding mode direct field-oriented control of six-phase induction motor. In: Proceedings of the SENE 2017: Sterowanie w Energoelektronice i Napędzie Elektrycznym, Lodz, Poland, 22-24 November 2017.

Listwan, J. and Pienkowski, K. (2016a). Direct FieldOriented Control of Six-Phase Induction Motor with Fuzzy-Logic Speed Controller. Power Electronics and Drives, 1(1), pp. 91-101.

Listwan, J. and Pienkowski, K. (2016b). SlidingMode Direct Field-Oriented Control of Six-Phase Induction Motor. Technical Transactions, 2-E, pp. 91-104.

Orlowska-Kowalska, T. (2003). Sensorless Induction Motor Drives. Wroclaw: Wroclaw University of Technology Press (in Polish).

Utkin, V. I., Guldner, J. and Shi, J. X. (1999). SlidingMode Control in Electromechanical Systems. New York: Taylor and Francis. 